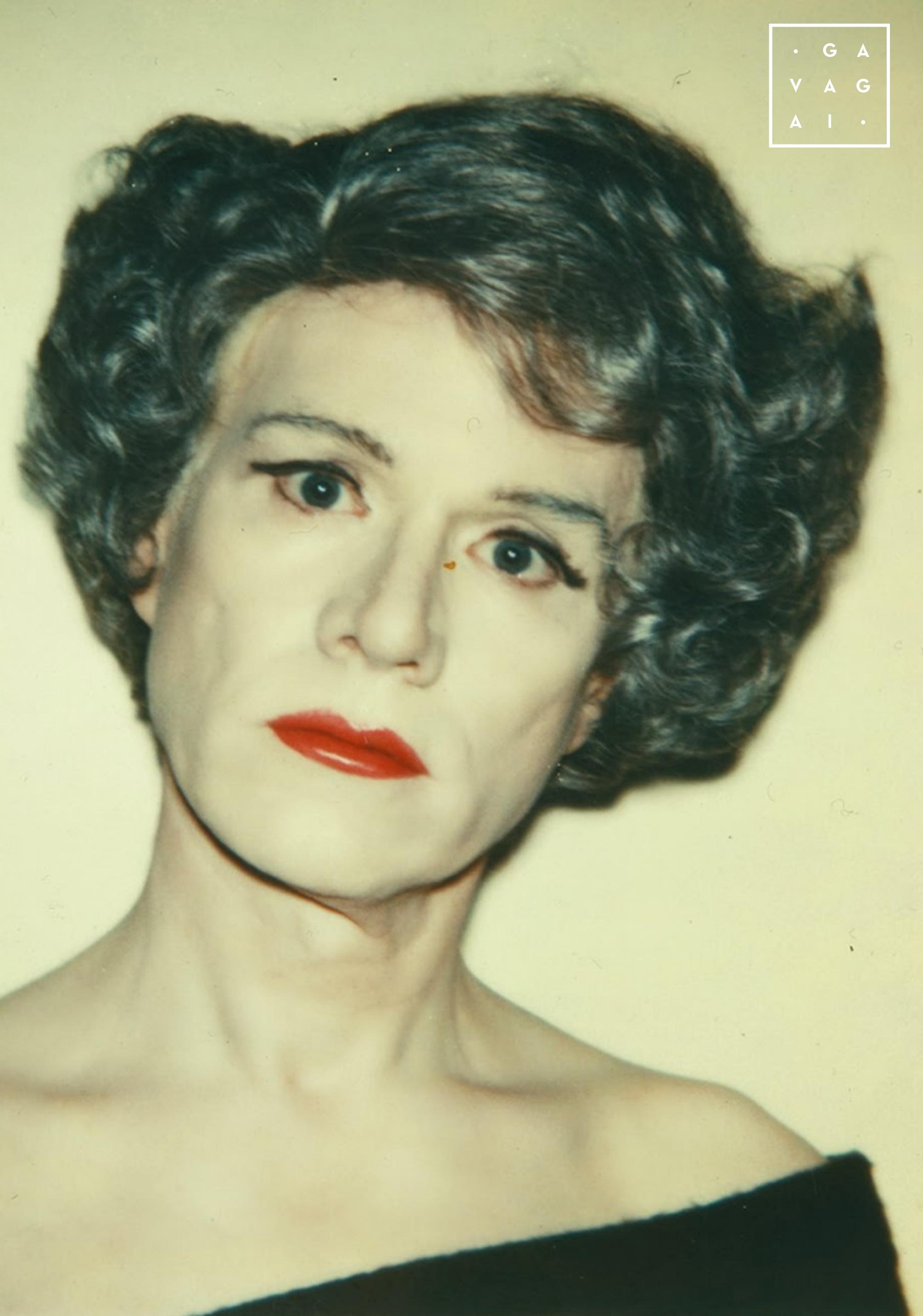




\section{HERMENÊUTICA RICOEURIANA E AS POLÍTICAS LINGUÍSTICAS}

HERMENÉUTICA RICOEURIANA Y LENGUAJE POLÍTICA

HERMENEUTICS AND LANGUAGE POLICY

Cristine Gorski Severo*

* Universidade Federal de Santa Catarina. Departamento de Língua e Literatura Vernáculas da Universidade Federal de Santa Catarina. E-mail: crisgorski@gmail.com. 
RESUMO / RESUMEN / ABSTRACT

Resumo: o artigo visa estabelecer uma aproximação entre a Política Linguística, enquanto campo de saber linguístico, e a hermenêutica, enquanto campo de saber filosófico. Trata-se de, a partir dos conceitos de linguagem e de hermenêutica do filósofo francês Paul Ricoeur, indagar a respeito da dimensão política e ética da Política Linguística. Com isso, são apresentados tantos os conceitos basilares da Política Linguística, como da filosofia ricoeuriana. Em seguida, propõe-se uma leitura crítica daqueles conceitos a partir da perspectiva filosófica, apontando para as fragilidades políticas e éticas das Políticas Linguísticas enquanto campo do saber que fornece argumentos "científicos" para políticas linguísticas estatais e jurídicas. Defende-se que a reflexão hermenêutica é crucial para redefinir, ou problematizar, aquilo que conta como língua para as Políticas Linguísticas.

Palavras-chave: Língua. Política. Hermenêutica. Linguística.

Resumen: El artículo tiene como objetivo establecer una conexión entre la política de idiomas, como el campo de conocimientos lingüísticos, y la hermenéutica, como el campo del conocimiento filosófico. El tema es, basado en los conceptos del lenguaje y la hermenéutica del filósofo francés Paul Ricoeur, cuestionar la dimensión política y ética de la política de idiomas. Con esto, se presentan aquí tanto los conceptos básicos de la política de idiomas, como de la filosofía ricoeuriana. A continuación se propone una lectura crítica de estos conceptos desde el punto de vista filosófico, señalando las debilidades políticas y éticas de la política lingüística como campo de conocimiento que proporciona argumentos "científicos" de las políticas del gobierno y del lenguaje jurídico. Se argumenta que la reflexión hermenéutica es crucial para restablecer, o hablar, lo que se considera un lenguaje de Política Lingüística.

Palabras clave: Lenguaje. Política. Hermenéutica. Lingüística.

Abstract: The purpose of this article is to approximate Language Policy, as a field of Linguistics, and Hermeneutics, as a field of Philosophy. For doing so, we consider the concepts of language and hermeneutics of French philosopher Paul Ricoeur to inquire about the political and ethical dimension of Language Policy. The article presents the basic concepts of Language Policy, as well as the concepts of language and comprehensio of Paul Ricoeur. From this philosophical perspective, we point to the political and ethical weaknesses of Linguistic Policy that provides "scientific" arguments for government and legal language policies. It is argued that the hermeneutical perspective is crucial to discuss what counts as a language for Language Policy.

Keywords: Language. Politics. Hermeneutics. Linguistics. 


\section{INTRODUÇÃO ${ }^{1}$}

Este texto tem como objetivo submeter as Políticas Linguísticas, enquanto campo disciplinar e político, às reflexões hermenêuticas sobre língua e linguagem. Trata-se de problematizar o conceito de língua, conforme articulado pela Linguística, a partir de um olhar filosófico centrado no pensamento de Paul Ricoeur (1913-2005). Com isso, busca-se aproximar Linguística e Filosofia em torno das reflexões sobre os conceitos de língua e de linguagem. Embora Filosofia e a Linguística se ocupem de objetos diferentes - a primeira se volta para o fato da existência da linguagem, e a segunda se detém sobre a língua e a descrição de suas propriedades gramaticais (MILNER, 2012) - acreditamos que tal diferença é crucial para submeter o conceito de língua da Linguística Moderna ao crivo de indagações filosóficas.

Importante frisar que, embora Paul Ricoeur compartilhe uma preocupação filosófica em torno da linguagem, suas reflexões não desconsideram a dimensão verbal, tão cara aos linguistas e teóricos da literatura. Nesse sentido, Paul Ricoeur é um filósofo que também se ocupa das questões linguísticas e literárias, muitas vezes negligenciadas pela Filosofia. A partir disso, considera-se que o diálogo estabelecido entre Filosofia, Linguística e Teoria Literária por Ricoeur nos ajuda a compreender as implicações éticas e políticas da Política Linguística enquanto campo de saber vinculado à Linguística.

Toma-se como hipótese de trabalho a suposição de que o processo hermenêutico, centrado em uma dada concepção de língua, permite repensar as práticas e discursos da Política Linguística, que são tradicionalmente vinculadas às instituições estatais e aos discursos científicos. Defende-se que a consideração da dimensão hermenêutica inscrita em um dado conceito de língua é crucial para que a Política Linguística se torne um campo efetivamente envolvido e afetado pela esfera pública, compreendida como um espaço compartilhado, dialógico, plural e definidor da dimensão política da condição humana (ARENDT, 2010).

O texto estrutura-se da seguinte maneira: inicialmente, apresenta-se o campo de saber da Política Linguística, apontando para seu caráter objetificante e reificador; em seguida, discorre-se sobre a perspectiva hermenêutica de Paul Ricoeur, com foco especial sobre seus conceitos de língua e de interpretação; por fim, consideram-se as possíveis contribuições e indagações do pensamento de Ricoeur para a

\footnotetext{
${ }^{1}$ Parte das reflexões do presente texto foram apresentadas no III
} Simpósio Internacional Hermeneia: Metafísica e virada linguística,
Política Linguística.

\section{SOBRE A POLÍTICA LINGUÍSTICA COMO CAMPO DE SABER}

A Política Linguística - como campo de saber vinculado, tradicionalmente, à área da Linguística - é constituída, de forma geral, por dois eixos interligados: Política Linguística e Planejamento Linguístico. O primeiro eixo tem se voltado para uma prática de caráter estatal-legislativo, se debruçando, por exemplo, sobre a oficialização de línguas através de instrumentos jurídicos, a escolha de alfabeto para a representação gráfica de uma língua, a hierarquização formal das línguas (línguas de trabalho, oficiais, nacionais, por exemplo), entre outros. O segundo eixo tem focado a implementação das decisões sobre a língua através de certas estratégias, como as políticas educacionais, com vistas a influenciar o comportamento dos sujeitos em relação à aquisição e uso dos códigos linguísticos (COOPER, 1989).

O "nascimento" da Política Linguística (PL) como campo científico disciplinar se deu concomitante à emergência da Sociolinguística, ambas tendo como marco um evento organizado por William Bright na Universidade da Califórnia em 1964. Embora a PL se vincule, tradicionalmente, a este contexto acadêmico norte-americano, é possível considerar a sua existência já no contexto russo pré-revolução de 1917, em que os linguistas da época ocupavam-se de instrumentalizar as línguas ágrafas com fins de fomentar a educação nessas línguas, bem como seu uso administrativo (REZNICK, 2001). A fase inicial de configuração da Política Linguística no Ocidente como um campo científico foi atravessada por esforços de sistematização e racionalização de um modelo aplicável aos estudos de descrição da relação entre as línguas e de seu funcionamento nos limites do Estado.

Tratou-se, portanto, de construir modelos explicativos, por exemplo, para a diversidade linguística em contextos nacionais, diante de uma realidade multilíngue produzida por imigrações; ou em contextos pós-independência, em que a língua foi tida como instrumento para a construção de uma unidade nacional. Exemplificando o processo de formação da Política Linguística como disciplina, os métodos de sistematização da relação entre as línguas incluíam classificações hierárquicas das línguas (vernácula, padrão, clássica, crioula, pidgin), das suas funções (língua de ensino,

realizado na Universidade Federal de Santa Catarina em agosto de 2015 
oficial, internacional, veicular, religião, gregária), de seus atributos, dos seus diferentes níveis de favorecimento/desfavorecimento (escala GIDS de Fishman), entre outros (CALVET, 2007; BIANCO, 2004). Embora o caráter polissêmico e plural da Política Linguística seja reconhecido academicamente (RAJAGOPALAN, 2013; SEVERO, 2013), observa-se que a prática de objetificação das línguas tem sido reiteradamente reproduzida e sustentada por esse campo de saber.

Contudo, as práticas de nomeação, classificação e de produção de conhecimentos sobre as línguas não nasceram no século $\mathrm{XX}$, tendo sido amplamente utilizadas como gestos de controle e de dominação inscritos em dispositivos coloniais. Exemplos disso foram a construção de gramáticas, alfabetos e listas de palavras com fins de conversão religiosa e/ou submissão política (ERRINGTON, 2008). A cientificização dos discursos e práticas sobre a diversidade linguística - e sua "gestão" levada a cabo pelos campos disciplinares de Política Linguística e Sociolinguística instauraram discursos sobre as línguas a partir de sua objetificação, embora a Linguística não seja a única área do saber a transformar a língua em objeto de pesquisa.

Curiosamente, o sintagma "gestão de línguas" é recorrente em artigos acadêmicos voltados para a Política Linguística. A título de exemplo, uma simples pesquisa no sistema de busca google revela a alta frequência da expressão, totalizando 305.000 ocorrências (pesquisa em 15 de janeiro de 2016). Evidentemente, uma análise mais detalhada seria necessária para averiguar os diferentes sentidos atribuídos ao sintagma "gestão de línguas", embora acredite-se que as possibilidades semânticas não extrapolem uma visão coisificante de língua. Essa objetificação e coisificação operada pela Linguística implica que a língua passa a ser tomada como uma realidade autônoma, contável, nomeável e passível de descrição (MAKONI; PENNYCOOK, 2007). Por outro lado, é preciso reconhecer que a reificação da língua pela Política Linguística tem sido alvo de contestação e questionamentos, embora de forma tímida, a partir de uma perspectiva de orientação crítica, conforme reivindicado por Rajagopalan (2013, p. 24): “A língua nacional não é um assunto de ciência; ela pertence à esfera política”.

Tendo feita essa breve apresentação do campo disciplinar, o presente texto pretende discorrer e refletir sobre a as dimensões política e ética da Política Linguística, a partir das lentes filosóficas de Paul Ricoeur. A despeito de as políticas

\footnotetext{
${ }^{2}$ Segundo Foucault (1999), nas sociedades modernas, o regime de verdade - ou a economia política dos enunciados verdadeiros apresenta cinco características: vincula-se ao discurso científico e às
}

linguísticas se referirem, também, a uma série de práticas, cotidianas e/ou institucionais, envolvendo as línguas e seus usos públicos e compartilhados, nesse artigo focaremos o campo disciplinar da Política Linguística, uma vez que ele tem funcionado como um forte orientador do "regime de verdade"2 (FOUCAULT, 1999) que define o que conta como língua na esfera das regulamentações e decisões institucionais. Exemplo disso são os documentos oficiais que, a pretexto de legislarem sobre as línguas, mobilizam saberes linguísticos (e não filosóficos ou cotidianos) para legitimarem seus discursos.

\section{LÍNGUA, TEXTO, DISCURSO E A HERMENÊUTICA DE PAUL RICOEUR}

Para Paul Ricoeur, as indagações a respeito da língua e da linguagem se inscrevem em um campo filosófico que busca "[...] compreender a dimensão da ação humana e sua implicação ética" (PAULA; SPERBER, 2011, p. 16). Nesse sentido, a hermenêutica, mais do que oferecer chaves de interpretação e decodificação de textos, "é um modo de ser" (PAUlA, 2012, p. 241). Com isso, as concepções de Ricoeur de língua e discurso se vinculam às dimensões ética e política atreladas a uma preocupação em torno da interpretação da dimensão simbólica, que opera, sobretudo, como uma interpretação de si (PAULA, 2012). O processo hermenêutico, para o filósofo francês, implica que os sujeitos estabelecem com os enunciados que os interpelam uma atitude responsiva e dialógica, o que viabiliza, pelo menos a princípio, um espaço de (re)constituição de si. Essa consideração do sujeito-leitorinterlocutor revela uma aproximação teórica do filósofo com a Estética da Recepção (PAULA; SPERBER, 2011).

Segundo Ricoeur, o processo hermenêutico envolvendo a linguagem verbal (língua) exige uma relação dialética entre dois níveis: o linguístico e o discursivo, ou o linguístico e nãolinguístico. Essa diferenciação conceitual entre língua e discurso implica, também, a consideração de dois níveis semânticos: a significação e o evento, em que estão em jogo duas temporalidades, a da tradição (repetição) e a da interpretação (renovação) (PAULA; SPERBER, 2011). A tensão, ou relação, entre esses dois níveis está vinculada a duas etapas de interpretação, a explicação e a compreensão. Essa tensão também coloca em tela a existência da pluralidade de interpretações, que extrapola a dimensão estritamente linguística do processo hermenêutico. Assim, explicação e

instituições que o produzem; é usado para interesses econômicos e políticos; é amplamente difundido e apropriado; é controlado por instâncias políticas e econômicas; e é alvo de tensões ideológicas. 
compreensão, como etapas do processo hermenêutico, estabelecem entre si uma relação dialética que é motivada por uma outra dialética, do evento e da significação, em que o discurso é tido como o evento da linguagem, e a significação como sistema.

A partir dessa apresentação inicial, consideremos as implicações da dimensão hermenêutica como constitutiva de noção de língua para a Política Linguística. De forma geral, o conceito de língua mobilizado pela Política Linguística tende a negligenciar a dimensão hermenêutica, objetificando a língua para fins de sua "gestão". Para discutir a noção de língua de Ricoeur, toma-se como base a obra Teoria da Interpretação (1973), na qual o filósofo desenvolve sua teoria hermenêutica, conferindo atenção especial para as especificidades linguísticas e a relação entre as dimensões verbal e não verbal.

O evento é único, singular, temporal e fugaz, enquanto o sistema é estável, virtual, atemporal e permanente, sendo que a língua se atualiza no discurso. Contudo, Ricoeur não considera essas duas realidades da linguagem como antagônicas, mas propõe uma constituição dialética (de evento e significação) para se compreender o funcionamento do discurso: se, por um lado, o discurso se atualiza em evento, por outro, o que se compreende é a significação (conteúdo proposicional). Trata-se de uma “[...] supressão e superação do evento na significação” (RICOEUR, 1973, p. 25) como atributo do discurso, em que se tem, por fim, uma linguística do discurso (e não do sistema).

Nessa relação dialética entre significado e evento, o evento fugaz e transitório passa a ser fixado e retido em significado, que é temporal. Assim, uma noção dialética de discurso comporta tanto a dimensão estrutural, como a intenção, a historicidade e o diálogo. No âmbito da hermenêutica, está em jogo a dialética da compreensão e explicação, em que ambas são tomadas como fases de um mesmo processo. Conforme visto, essa dialética é comparável à dialética do evento e da significação: “[...] a compreensão é para a leitura o que o evento do discurso é para a enunciação do discurso, e a explicação é para a leitura o que a autonomia verbal e textual é para o sentido objetivo do texto" (RICOEUR, 1973, p. 102).

Sobre a dialética significado-evento, Ricoeur questiona: "que aspectos do próprio discurso são significativamente comunicados no evento do diálogo?" (RICOEUR, 1973, p. 30). Em diálogo com a abordagem dos atos de fala de Austin, comunica-se, em uma dialética subjetiva-objetiva: (i) o conteúdo proposicional do discurso, sendo que a ambiguidade das palavras é reduzida pelo papel contextual do diálogo; (ii) o ato ilocutório, em que as intenções do sujeito, como as ordenações, os desejos, as proibições, as promessas, etc., são materializadas na gramática, na pontuação, nos sinais de citação, na prosódia, na expressividade, entre outros; (iii) o ato perlocutório, que trata do que é efetivamente produzido pelo ato de fala, sendo mais sutil e menos decifrável linguisticamente. Embora elementos linguísticos escritos e orais sejam mencionados, interessa ao filósofo, inicialmente, aplicar a sua concepção dialética de discurso ao texto escrito, em que o texto é tomado como uma forma de discurso.

Ricoeur descreve o processo de compreensão em dois estágios mediados pela explicação: primeiro dá-se a conjectura e depois a apropriação. A conjectura, uma tentativa de adivinhação do texto, é motivada pelo apagamento da intenção do autor e, consequentemente, pelo fortalecimento de uma relação entre o leitor e o texto, configurando um novo acontecimento. Nas palavras de Ricoeur (1973, p. 107): “Construir o sentido verbal do texto é fazer uma conjectura”, que se apoia tanto em uma certa adivinhação, como na estrutura gramatical do texto. Esta construção de sentido (i) não opera de forma fragmentada, mas sobre o todo do texto, considerando a sua plurivocidade; (ii) exige uma individualização do texto, que ocorre segundo a relação entre regras singulares e genéricas; (iii) opera de forma diferenciada nos textos literários, em que os sentidos podem ser atualizados de diferentes maneiras, uma vez que se trata de sentidos metafóricos e simbólicos. As conjecturas do texto podem ser ou não validadas, em que uma dada interpretação pode se aproximar mais ou menos do que é provável de ser aceito, independente de ser mais ou menos verdadeiro, uma vez que há limites para as construções possíveis de um texto. A dialética da conjectura (como instância da compreensão e, portanto, do evento) e da validação (como instância da explicação e, logo, da significação) espelham tratamentos subjetivo (conjectura), objetivo (explicação) e subjetivoobjetivo (compreensão) do texto.

Sobre a especificidade dos textos escritos literários, tem-se que a dimensão da referencialidade é estremecida pelo apagamento de uma situação real entre o autor e o leitor, o que faz com que o mundo, abstraído da realidade, seja simbolicamente transportado para a linguagem. Essa abstração produz dois modos de leitura: suspensão de referência à realidade ou atualização de outras referências em uma nova situação produzida pelo ato de leitura

O primeiro tipo de leitura compreende o nível da explicação e, ao apagar a relação com o mundo e a intenção do autor, esvazia o texto de um exterior que, assim, passa a ser tomado em si mesmo, como um sistema estrutural fechado de signos, similar 
à langue de Saussure. A leitura estrutural - como a análise dos mitos feita por Levi-Strauss ou das narrativas folclóricas por Roland Barthes e Greimas - possibilita a extração da lógica das operações e das relações (hierarquizadas) estabelecidas no texto, o que não encerra o trabalho de interpretação.

O segundo tipo de leitura compreende o nível da compreensão e possibilita a atualização de "[...] referência a alguns aspectos ou dimensões mais profundamente radicados do nosso ser-nomundo" (RICOEUR, 1973, p. 113); essa atualização possibilita desvendar um outro mundo possível, que é o próprio sentido do texto, não localizado detrás do texto ou oculto nele, mas na sua frente: "O texto fala de um mundo possível e de um modo possível de alguém nele se orientar” (RICOEUR, 1973, p. 122). Essa segunda leitura aplicada à interpretação estrutural dos mitos, por exemplo, sinaliza para um outro sentido, de situações-limite, em que os mitos são tomados como narrativas de origens. Sobre a relação entre esses dois níveis de leitura, Ricoeur afirma:

Se [...] considerarmos a análise estrutural como um estágio - se bem que necessário - entre uma interpretação ingênua e uma interpretação crítica, entre uma interpretação de superfície e uma interpretação de profundidade, seria então possível localizar a explicação e a compreensão em dois estágios diferentes de um arco hermenêutico único (RICOEUR, 1973, p. 121).

O que se tem é que a explicação do texto, como um primeiro estágio da leitura, abre caminhos para a compreensão do texto. O sentido do texto abre uma nova referência, um novo olhar, em que "mostrar é ao mesmo tempo criar um novo modo de ser" (RICOEUR, 1973, p. 123). Eis a dimensão ética inscrita na leitura do texto literário, em que a interpretação do texto conduz o sujeito a um certo conhecimento de si mesmo.

Importante salientar, ainda, que Ricoeur considera algumas diferenças entre a oralidade e a escrita que devem ser especialmente consideradas no âmbito da discussão apresentada neste artigo, uma vez que os registros formais e oficiais são constitutivos do sistema burocrático dos estados modernos em que a escrita opera como tecnologia de poder (FOUCAULT, 1999a). Diferenciando textos escritos de práticas orais, tem-se:

(i) Na fala, o discurso é um evento que desaparece; na escrita, o discurso é fixado como significação, e não como evento, logo, o texto torna-se um discurso fixado pela escrita (RICOEUR,

\footnotetext{
3 "Here again the spirituality of discourse manifests itself through writing, which frees us from the visibility and limitation of situations by opening up a world for us, that is, new di-mensions of our beingin-the-world". As traduções são de minha responsabilidade.
}

1981)

(ii) $\mathrm{Na}$ oralidade há a sobreposição entre a intenção do sujeito e o significado do discurso. Já no texto escrito, esta combinação não ocorre, o que complexifica a relação entre o sujeito e o texto. Assim, havendo a emancipação do texto em relação à intenção do autor, a significação do texto torna-se responsável pela construção do seu sentido, abrindo espaço para que a interpretação aconteça.

Se, por um lado, a fala tem uma referência contextual específica e direta, por outro, o texto escrito não compartilha essa mesma referência, uma vez que está livre do contexto imediato de sua produção. A referência do texto é dada pelo ato de leitura e de interpretação. Dessa forma, a autonomia do texto em relação à realidade conduz a uma outra autonomia, em que o texto abre novas referências para o mundo, o que significa que ele instaura novos modos de ser e de ver o mundo. Trata-se, com isso, da emancipação do texto em relação à situação imediata de diálogo:

Aqui, novamente, a espiritualidade do discurso se manifesta através da escrita, a qual nos liberta da visibilidade e da limitação das situações ao abrir para nós um mundo, ou seja, novas dimensões do nosso ser-nomundo3 (RICOEUR, 1981, p. 202).

(iii) A fala direciona-se para um interlocutor específico e o texto direciona-se para qualquer leitor possível, muito embora haja, nesse direcionamento, um leitor "presumido" (VOLOSHINOV, 1981). Trata-se da emancipação do texto em relação ao interlocutor ou a algum leitor original.

A principal consequência hermenêutica dessa tripla autonomia do texto é o distanciamento (do autor, da situação e do leitor), que opera como condição tanto de interpretação e de re-criação do mundo, como de entendimento de si diante do texto, ao promover um distanciamento do ser em relação a si mesmo, uma vez que: "a apropriação dos mundos sugeridos pelo texto passa pela desapropriação de si mesmo"4 (RICOEUR, 1981, p. 94). Nesse contexto, a apropriação significa tornar meu o que uma vez foi alheio, expandindo o ser. Esse aspecto desconstroi a ideologia de um sujeito centrado.

Resumidamente, Paul Ricoeur incorpora ao processo hermenêutico dois níveis de leitura dialeticamente implicados: a explicação e a compreensão, sendo que o primeiro se torna condição para o segundo, estando a dimensão ética de

\footnotetext{
4 "the appropriation of the proposed worlds offered by the text passes through the disappropriation of the self."
} 
(re)criação de si inscrita no segundo. O filósofo localiza, embora não unicamente, a dimensão ética na esfera textualliterária, uma vez que no âmbito da escrita literária ficcional, os sujeitos podem ser levados, pelo ato de compreensão, a uma reconfiguração de si, possibilitando uma mudança de visão de mundo e de modo de ser pelo confronto do sujeito com a abertura de um mundo possível viabilizada pelo texto literário.

A seguir, serão consideradas as implicações dessa perspectiva de Ricoeur para a Política Linguística, colocando em tela a importância da dialética entre significação-evento e explicação-compreensão, como lugar de produção e ressignificação de sentidos e dos sujeitos.

\section{3 ÉTICA, POLÍTICA E AS POLÍTICAS LINGUÍSTICAS}

Tendo feito a explanação da noção de língua subjacente ao processo hermenêutico de Ricoeur, trata-se, por fim, de refletir sobre suas implicações para a Política Linguística. Advoga-se a favor de um conceito de língua que tome a dimensão hermenêutica como constitutiva das reflexões em Política Linguística, de forma que as práticas e discursos em torno da oficialização, estabilização, normatização, promoção ou defesa da língua não impliquem um fechamento dos sentidos.

Se, por um lado, as políticas linguísticas estatais têm se apoiado em uma noção de língua estrutural (níveis linguísticos) e cujos sentidos são passíveis de estabilização relativa (instrumentos linguísticos de normatização), por outro lado, no "mundo da vida", a língua funciona não como langue (estrutura), mas como enunciado (discurso). Contudo, esses dois níveis não operam de forma desarticulada, mas, na visão de Ricoeur, estabelecem uma relação dialética.

Ocorre que a objetificação produzida pela Política Linguística, enquanto campo de saber, em torno do conceito de língua produz um apagamento dos sujeitos - da enunciação, da história e da política -, fato que tem consequências para as políticas linguísticas, enquanto práticas sociais de intervenção cotidiana. A concepção de língua de Ricoeur - vinculada à hermenêutica e ao processo de subjetivação - nos ajuda a refletir criticamente sobre as consequências (políticas e éticas) das políticas estatais que envolvem, por exemplo, os falantes de línguas consideradas minoritárias no Brasil, como são as línguas indígenas, língua de Sinais (LIBRAS), línguas de imigrantes ou de comunidades quilombolas.
Um outro exemplo a explorar é o caso da política de patrimonialização das línguas - tomadas como bens culturais -, que pode ser problematizada em relação a, pelo menos, três aspectos, cujos efeitos políticos devem ser considerados: (i) reificação da língua; (ii) submissão das línguas a um discurso nacionalista; (iii) cristalização da relação entre língua, cultura, falantes e território. Nesse contexto, se as línguas são objetificadas pelas políticas oficiais, como fica a voz desses sujeitos? Considera-se que uma abordagem hermenêutica da linguagem possibilita considerar o papel da linguagem na configuração ética e política dos sujeitos. A reificação da língua como ato estatal político opera produzindo silenciamentos na cena pública, uma vez que divorcia a língua dos sujeitos. Ou seja, ironicamente, a política da Política Linguística opera pela censura, pelo silenciamento e pela uniformização linguísticodiscursiva, embora defenda, retoricamente, a diversidade linguística e os direitos linguísticos. Usamos, aqui, a construção "linguístico-discursiva" hifenizada, pois compreendemos, juntamente com Ricoeur, que a relação entre língua e discurso é dialética, afetando, diretamente, o processo hermenêutico.

Em outros termos, a política exercida pela Política Linguística - enquanto discursos científicos e institucionais objetificantes - impediria que os sujeitos se constituíssem de forma plural e livre. A visão objetificante de língua impede uma perspectiva dialética, que atua pela abertura e ressignificação dos sentidos. Ademais, defende-se que essa abertura, por sua vez, produz efeitos sobre o próprio sistema linguístico, colocando em xeque as normatizações e cristalizações linguísticas de políticas engessadas ou engessadoras, como tendem a ser os instrumentos linguísticos (gramáticas, dicionários, manuais de ensino e de redação). Exemplos dessa reconfiguração linguística são as hibridizações literárias, muito recorrentes em textos literários pós-coloniais.

Se, por um lado, as políticas patrimoniais ou normatizadoras operam apagando o evento (discurso) em prol de uma valorização do significado (sistema), por outro, no mundo público dos atos e discursos, os sujeitos se apropriam da língua como forma de resistência política e como modo de subjetivação, conforme nos mostra Franz Fanon (2008, p. 33) em relação aos usos políticos da língua, que extrapolam o domínio estrutural, embora se apoiem nele: "Falar é estar em condições de empregar um certa sintaxe, possuir a morfologia de tal ou qual língua, mas é sobretudo assumir uma cultura, suportar o peso de uma civilização." A voz falada e o discurso enunciado são políticos e, portanto, constitutivos da pólis e da vida compartilhada. A consideração da dimensão hermenêutica da linguagem possibilita também compreender 
o papel político da palabre, entendido como o costume que africanos ocidentais têm de reunir para resolver os problemas comuns através da palavra (FANON, 2008).

Embora Ricoeur tenha focalizado a sua atenção em textos ficcionais escritos, considera-se que seu conceito de texto extrapola a dimensão escrita e inclui as práticas linguísticas orais compartilhadas. A presença da voz, do corpo, dos gestos, da entonação e dos interlocutores na produção de discursos orais sinaliza para a importância de se inscrever a dimensão extra-verbal no processo de interpretação dos sentidos. Por outro lado, esses sentidos se apoiam em uma certa estabilidade (semântica e gramatical), que se torna condição para que o discurso se materialize.

Por fim, diante do apresentado, considera-se que o processo hermenêutico - embora esteja centrado no sujeito, constituindo-o como tal - é complementado por aquilo que é dado a ser interpretado. No caso deste artigo, a linguagem (a língua verbal escrita ou oral) carrega especificidades (diferente das linguagens visuais, musicais, etc.) que orienta os limites do processo hermenêutico. Isso implica considerar que a interpretação não é livre, mas relativamente controlada pelos limites estruturais da língua (explicação) em relação dialética com os limites históricos e dialógicos dos sentidos (compreensão). Embora o ato de interpretar seja constitutivo dos sujeitos, esse ato opera nos limites da tensão entre tradição e interpretação.

\section{PALAVRAS FINAIS}

Este artigo teve como objetivo indagar, a partir das lentes de Paul Ricoeur, a respeito da possibilidade de uma Política Linguística, enquanto campo do saber, que opere pelo não controle e fechamento (político) dos sentidos ou de sua cristalização, garantindo, com isso:

(i) A pluralidade linguística e discursiva, uma vez que "[...] a humanidade é irredutivelmente plural” (RICOEUR, 1995, p. 152), sendo que a pluralidade linguística não é vista como um "problema" para a comunicação e compreensão, mas como sua condição necessária, pois “[...] não há língua que não possa ser dublada por outra, que não possa encontrar em outra língua equivalência de sentido" (RICOEUR, 1995, p. 153). Decorre disso que os sentidos se realizam no evento único do enunciado e não estão amarrados unicamente ao sistema linguístico, embora se apoiem no sistema. Logo, a descrição linguística, que opera segundo uma concepção puramente estrutural, apaga os sentidos singulares e únicos, que dizem respeito às relações comunicativas do "mundo da vida". Uma política linguística que desconsidera as práticas linguísticodiscursivas torna-se incapaz de promover, efetivamente, a circulação das línguas no espaço público, conforme se percebe nas limitações dos projetos de promoção de línguas consideradas minoritárias em contextos pós-coloniais. Isso ocorre porque tais políticas reduzem-se à objetificação de línguas pela descrição e documentação do código.

(ii) A pluralidade de sentidos e a garantia da ambiguidade, da polissemia e da plurivocalidade como política e eticamente constitutivos da língua e da compreensão. Trata-se de uma política que opera pela promoção de práticas linguísticas que funcionem a favor da abertura dos sentidos, o que se evidencia, mais fortemente, nas práticas de leitura de textos ficcionais. Essa abertura dos sentidos, em relação às práticas orais, coloca em tela o papel do diálogo - tão caro à dimensão política do convívio plural entre as pessoas - para o processo hermenêutico.

(ii) A liberdade de relação dos sujeitos com seu projeto discursivo no mundo da vida e da arte. Com isso, as políticas linguísticas operariam pela promoção e manutenção da pluralidade e dos discursos. O que está em questão, portanto, é a redefinição daquilo que conta como língua para a Política Linguística enquanto campo do saber. Para tanto, considerase que um diálogo com a filosofia ricoeuriana possibilita considerar a tensão entre as dimensões linguística e nãolinguística como essencialmente vinculada ao problema hermenêutico e de configuração dos sujeitos.

Contudo, por fim, indaga-se em que medida essa dimensão ética pode ser efetivamente incorporada por uma Política Linguística enquanto prática estatal e jurídica. O que parece estar em jogo como desafio para a Política Linguística é estabelecer relações entre política - entendida como "[...] o exercício da decisão e da força no nível da comunidade" (RICOEUR, 1995, p. 148) - e ética. Tais relações são, conforme previsto por Ricoeur (1995, p. 148), "difíceis e cheias de armadilhas".

\section{REFERÊNCIAS}

ARENDT, Hannah. A condição humana. Trad. de Roberto Raposo. 8. ed. Rio de Janeiro: Forense Universitária, 2010.

BIANCO, J. L. Language planning as applied linguistics. In: DAVIES, A.; ELDER, C. (Org.). The handbook of applied 
linguistics. Oxford: Blackwell Publishing, 2004. p.738-762.

CALVET, Louis-Jean. As políticas linguísticas. São Paulo: Parábola/IPOL, 2007.

Mikhaïl Bakhtine, le principe dialogique, suivi de Ecrits du cercle de Bakhtine. Paris: Seuil, 1981. p. 181-215.

ERRINGTON, Joseph. The linguistic in the colonial: A Story of Language, Meaning, and Power. Oxford: Blackwell, 2008.

FOUCAULT, Michel. Verdade e poder. In: M. FOUCAULT. Microfísica do poder. 14. ed. Rio de Janeiro, Graal, 1999. p. 114.

Vigiar e punir [1975]. Petrópolis: Vozes, 1999a.

FANON, Franz. Pele negra, máscaras brancas [1952]. Trad. Renato da Silveira. Salvador: EDUFBA, 2008.

MAKONI, Sinfree; PENNYCOOK, Alastair (Org.). Disinventing and reconstituting languages. Clevedon: Multilingual Matters, 2007.

MILNER, Jean-Claude. O amor da língua. Trad. Paulo Sérgio de Souza Júnior. Campinas/SP: Editora da Unicamp, 2012.

PAULA, Adna Candido de. A teoria da interpretação e a hermenêutica bíblica de Paul Ricoeur. Teoliterária, v. 2, n. 4, 2012. p. 240-252.

PAULA, A. C.; SPERBER, Suzi Frankl (Org.). Teoria literária e hermenêutica ricoeuriana: Um diálogo possível. Dourados: EDUFGD, 2011. v. 1. 284p.

RAJAGOPALAN, Knavaillil. Política linguística: do que é que se trata, afinal? In: NICOLAIDES. Christine et al. Politica e políticas linguísticas. Campinas: Pontes, 2013. p. 19-42.

REZNIK, Vladislava. Language policy and reform in the Soviet 1920s: Practical polemics against idealist linguistics. Cambridge: 2001 (conferência).

RICOEUR, Paul. Teoria da interpretação: o discurso e o excesso de significação. Lisboa: Edições 70, 1973.

Hermeneutics and the human sciences: essays on language, action, and interpretation. Cambridge: Cambridge University Press, 1981.
COOPER, Robert. Language planning and social change. Cambridge: Cambridge University Press, 1989.

et le discours dans la poésie (1926). In: TODOROV, Tzvetan.

Leituras 1. Em torno ao político. São Paulo: Loyola, 1995.

SEVERO, Cristine Gorski. Política(s) linguísticas(s) e questões de poder. Alfa: Revista de Linguística (UNESP. Online), v. 2, n. 57, p. 451-473, 2013. Disponível em: $<$ http://seer.fclar.unesp.br/alfa/article/viewFile/5132/4670>. Acesso em: 25 jan., 2016.

VOLOSHINOV, Valentin Nikolaevich. Le discours dans la vie et le discours dans la poésie (1926). In: TODOROV, Tzvetan. Mikhail Bakhtine, le principe dialogique, suivi de Ecrits du cercle de Bakhtine. Paris: Seuil, 1981. p. 181-215. 